\title{
Multiresistant-MRSA tricuspid valve infective endocarditis with ancient osteomyelitis locus
}

\author{
Giuseppe Chesi ${ }^{1}$, Andrea Colli*2, Carlos A Mestres ${ }^{3}$, Gianpaolo Gambarati ${ }^{1}$, \\ Fabrizio Boni ${ }^{1}$ and Tiziano Gherli ${ }^{2}$
}

Address: ${ }^{1}$ Department of Internal Medicine, "C. Magati" Hospital, Via Martiri della libertà 8, 42019 Scandiano (RE), Italy, ${ }^{2}$ Department of Cardiac Surgery, University of Parma, Via Gramsci 13, 43100 Parma, Italy and ${ }^{3}$ Department of Cardiovascular Surgery, Hospital Clinic, Villaroel 170, 08036 Barcelona, Spain

Email: Giuseppe Chesi - GIUSEPPE.CHESI@ausl.re.it; Andrea Colli* - colli.andrea@libero.it; Carlos A Mestres - cmestres@clinic.ub.es; Gianpaolo Gambarati - gianpaolo.gambarati@ausl.re.it; Fabrizio Boni - fabrizio.boni@ausl.re.it; Tiziano Gherli - tiziano.gherli@unipr.it

* Corresponding author

Published: 26 July 2006

BMC Infectious Diseases 2006, 6:124 doi:10.1186/147|-2334-6-124
Received: 25 November 2005

Accepted: 26 July 2006

This article is available from: http://www.biomedcentral.com/I47I-2334/6/I24

(c) 2006 Chesi et al; licensee BioMed Central Ltd.

This is an Open Access article distributed under the terms of the Creative Commons Attribution License (http://creativecommons.org/licenses/by/2.0), which permits unrestricted use, distribution, and reproduction in any medium, provided the original work is properly cited.

\begin{abstract}
Background: Methicillin-resistant S. aureus (MRSA) with low susceptibility to glycopeptides is uncommon.

Case presentation: The case of a 50-year-old non-drug addict patient presenting with tricuspid valve infective endocarditis (IE) by MRSA resistant to vancomycin and linezolid is presented. There was response only to quinupristin/dalfopristin. He had a motorcycling accident four years before undergoing right above-the-knee amputation and orthopaedic fixation of the left limb. There were multiple episodes of left MRSA-osteomyelitis controlled after surgery and vancomycin therapy. MRSA isolated from the blood at the time of IE presented with the same profile than the isolated four years earlier. Sequential treatment with teicoplanin-cotrimoxazole and Linezolid associated to vancomycin - rifampicin - cotrimoxazole had no improvement. Infection was controlled after 28 days of therapy with quinupristin/dalfopristin.

Conclusion: The literature presents only a few cases of MRSA IE not susceptible to glycopeptides in not drug addicted patients. This case shows the comparison of a highly-resistant MRSA after previous $S$. aureus osteomyelitis treated with glycopeptides. This is the first description of successful treatment of resistant-MRSA IE of the tricuspid valve complicated by multiple pulmonary septic infarction with quinupristin/dalfopristin
\end{abstract}

\section{Background}

Infective endocarditis was an invariably fatal infection before the availability of antimicrobials. A significant percentage of patients still succumb to it despite aggressive treatment especially when infected with virulent organisms such as Staphylococcus aureus. Overall, approximately $20 \%$ of S. aureus isolates in Europe are reported as methicillin-resistant, whereas in US hospitals the prevalence ranges from $33 \%$ to $55 \%$. The past few years have also witnessed an increase in life-threatening communityacquired infections caused by MRSA. Most infections with VISA (vancomycin-intermediate $S$. aureus) and VRSA (vancomycin-resistant S. aureus) have occurred in a setting of heavy prior use of glycopeptides and other antimicrobial agents. Emergence of reduced vancomycin susceptibility and clinical resistance in S. aureus increases 
the possibility that currently available antimicrobial agents may become ineffective for treating systemic infections.

\section{Case presentation}

A 50 year-old non-insulin dependant diabetic male was admitted with the chief complaints of three-day fever and poor general status. He had a 3/6 diastolic murmur over the xyphoid process. Chest X-ray did not show abnormalities. Abdominal ultrasound showed splenomegaly. His past history included the following: In June 2000 he had a road traffic accident resulting in multiple trauma, requiring right above-the-knee amputation and orthopaedic fixation of the left lower limb. He later presented with multiple episodes of osteomyelitis of this limb treated with iv. antibiotics. Prosthetic shafts were removed in June 2002 and MRSA isolated. Three months later he presented with a spontaneous fracture of the limb and required new surgical fixation due to infectious pseudoarthrosis. MRSA was isolated again. In October 2003 he was re-operated and underwent auto-transplantation of corticospongiosa. During these episodes he was given teicoplanin, cotrimoxazole, rifampicin, tetracycline and quinolones at intervals of 7 to 20 days at another institution in a distant site. Table 1 shows the summary of the multiple events.

In June 2004 he was admitted to our institution with the above mentioned complaints. Transthoracic echocardiography (TTE) showed a large vegetation (size $2.5 \times 0.8 \mathrm{~cm}$ ) on the anterior leaflet of the tricuspid valve (Figure 1) and severe valve insufficiency, with a normal left ventricular ejection fraction. Transesophageal echocardiography (TEE) disclosed other pathologic findings. A total body computed tomography scan was performed showing multiple bilateral areas suggesting pulmonary infarction (Figure 2). A labelled leucocyte scintigraphy didn't reveal any specific infective localization.

The patient was treated with an association of oxacillin 16 gr/day and gentamycin $240 \mathrm{mg} /$ day that was shifted two days later to teicoplanin $(1200 \mathrm{mg} / 12 \mathrm{~h} / \mathrm{IV})$ for the first 3 days followed with $1200 \mathrm{mg} /$ day/IV) and cotrimoxazole (480 mg/12 h/IV) as MRSA was isolated. The MRSA was resistant to clindamycin $(\mathrm{MIC}>8 \mathrm{mcg} / \mathrm{ml})$, erythromycin $(\mathrm{MIC}>8 \mathrm{mcg} / \mathrm{ml})$, gentamycin $(\mathrm{MIC}>16 \mathrm{mcg} / \mathrm{ml})$, norfloxacin (MIC>16 mcg/ml), ofloxacin (MIC>8 mcg/ml), oxacillin (MIC $>4 \mathrm{mcg} / \mathrm{ml}$ ), penicillin (MIC $>0.8 \mathrm{mcg} / \mathrm{ml}$ ), and tobramycin $(\mathrm{MIC}>16 \mathrm{mcg} / \mathrm{ml})$. The MRSA resulted susceptible to rifampicin (MIC $<0.5 \mathrm{mcg} / \mathrm{ml})$, teicoplanin $(\mathrm{MIC}<0.5 \mathrm{mcg} / \mathrm{ml})$, tetracicline $(\mathrm{MIC}<1 \mathrm{mcg} / \mathrm{ml})$, cotrimoxazole $(\mathrm{MIC}<10 \mathrm{mcg} / \mathrm{ml})$ and vancomycin $(\mathrm{MIC}<1$ $\mathrm{mcg} / \mathrm{ml}$ ). Linezolid $600 \mathrm{mg}$ daily iv was started 8 days later because of worsening condition (Linezolid was not tested in-vitro). However this proved to be ineffective as the patient still presented fever and positive blood cultures for MRSA maintaining the same strains. A new TTE was performed showing the presence of a new vegetation on the anterior leaflet of the tricuspid valve.

Table I: Summary of multiple events

\begin{tabular}{|c|c|c|c|c|}
\hline Period & $\begin{array}{l}\text { Hospital } \\
\text { Admission }\end{array}$ & Cause & $\begin{array}{l}\text { Isolated } \\
\text { pathogen }\end{array}$ & Antibiotic therapy \\
\hline June 2000 & $\mathrm{ICU}$ & Road Traffic accident & - & - \\
\hline $\begin{array}{l}\text { August } 2000- \\
\text { December } 2000\end{array}$ & Rehabilitation Unit & $\begin{array}{l}\text { Rehabilitation, Orthopaedic } \\
\text { fixation, osteomyelitis left } \\
\text { leg }\end{array}$ & - & $\begin{array}{l}\text { Ciprofloxacin } 500 \mathrm{mg} / 12 \mathrm{~h} / 2 \mathrm{I} \text { days } \\
\text { Amoxicillin/clavulanic acid I } \mathrm{g} / \mathrm{/} 2 \mathrm{~h} / 28 \text { days }\end{array}$ \\
\hline June 2002 & Orthopaedic Unit & Re-Orthopaedic fixation & MRSA & $\begin{array}{l}\text { Minocycline } 100 \mathrm{mg} / 12 \mathrm{~h} / 14 \text { days } \\
\text { Cotrimoxazole } 480 \mathrm{mg} . / 12 \mathrm{~h} / 8 \text { days } \\
\text { Teicoplanin } 200 \mathrm{mg} / 24 \mathrm{~h} / 8 \text { days }\end{array}$ \\
\hline September 2002 & Orthopaedic Unit & $\begin{array}{l}\text { Spontaneous limb fracture } \\
\text { - Orthopaedic fixation }\end{array}$ & MRSA & $\begin{array}{l}\text { Teicoplanin } 400 \mathrm{mg} / 24 \mathrm{~h} / 8 \text { days } \\
\text { Rifampicin } 600 \mathrm{mg} / \mathrm{/} 2 \mathrm{~h} / 10 \text { days }\end{array}$ \\
\hline $\begin{array}{l}\text { February } 2003- \\
\text { May } 2003\end{array}$ & Rehabilitation Unit & Rehabilitation & - & 0 \\
\hline October 2003 & Orthopaedic Unit & $\begin{array}{l}\text { Autotransplantation of } \\
\text { corticospongiosa }\end{array}$ & MRSA & $\begin{array}{l}\text { Ciprofloxacin } 500 / 12 \mathrm{~h} / 14 \text { days } \\
\text { Teicoplanin } 200 \mathrm{mg} / 24 \mathrm{~h} / 8 \text { days }\end{array}$ \\
\hline $\begin{array}{l}\text { June } 2004- \\
\text { August } 2004\end{array}$ & $\begin{array}{l}\text { Internal Medicine } \\
\text { Unit and Cardiac } \\
\text { Surgery Unit }\end{array}$ & Tricuspid valve endocarditis & MRSA & $\begin{array}{l}\text { Cefixime } 800 \mathrm{mg} / 2 \text { days } \\
\text { Oxacillin } 16 \mathrm{~g} / 24 \mathrm{~h} / 3 \text { days }+ \text { Gentamycin } 240 \mathrm{mg} / 24 \mathrm{~h} / 3 \\
\text { days } \\
\text { Teicoplanin } 1200 \mathrm{mg} / 24 \mathrm{~h} / 8 \text { days + Cotrimoxazole } 960 \\
\mathrm{mg} / 24 \mathrm{~h} / 8 \text { days } \\
\text { Linezolid } 600 \mathrm{mg} / 24 \mathrm{~h} / 7 \text { days } \\
\text { Vancomycin } 3 \mathrm{~g} / 24 \mathrm{~h} / 12 \text { days }+ \text { Rifampicin } 600 \mathrm{mg} / 24 \mathrm{~h} / \\
12 \text { days+ Cotrimoxazole } 1440 \mathrm{mg} / 24 \mathrm{~h} / 12 \text { days } \\
\text { Quinupristin/dalfopristin } 750 \mathrm{mg} / 8 \mathrm{~h} / 36 \text { days }\end{array}$ \\
\hline
\end{tabular}




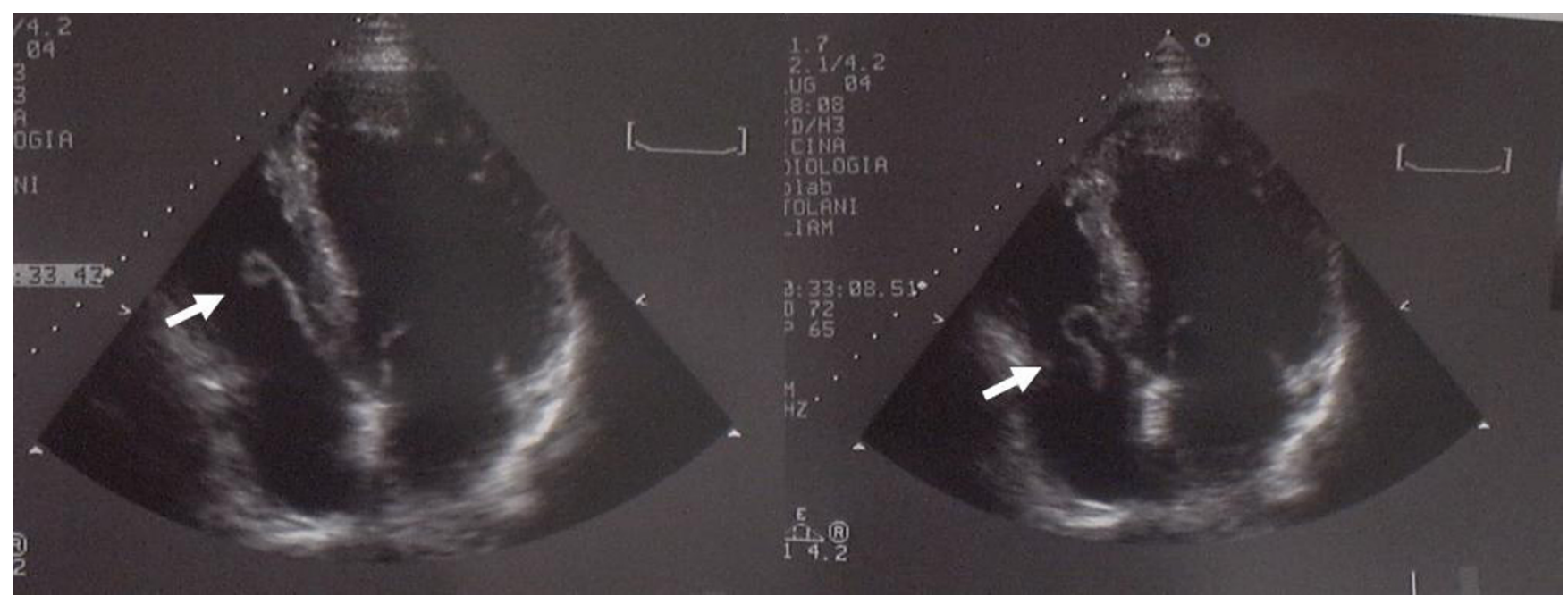

Figure I

Transthoracic echocardiogram showing a vegetation on the septal leaflet of the tricuspid valve.

Linezolid was then replaced with vancomycin $(500 \mathrm{mg} / 6$ $\mathrm{h} / \mathrm{IV})$, rifampicin (600 $\mathrm{mg} / 8 \mathrm{~h} / \mathrm{IV})$ and cotrimoxazole (480 mg/8 h/IV) that was again ineffective and after 12 days of therapy was suspended. After 27 days of ineffective therapy the patient condition was very poor; TTE showed new vegetations on the posterior leaflet of the tricuspid valve with severe insufficiency and large pulmonary infarctions. Quinupristin/dalfopristin were at $7.5 \mathrm{mg}-\mathrm{Kg} / 8$ h/IV. After three days of therapy the patient became afebrile and his condition improved. After 25 days of therapy with quinupristin/dalfopristin, biological markers for infection became normal and the patient underwent left above-the-knee amputation as prevention treatment for new infections. The therapy with quinupristin/dalfopris- tin was suspended after 42 days. A Transesophageal echocardiography and a thoracic computed tomography scan were performed at the end of antibiotic therapy and at 18 months after discharge showed complete regression of the tricuspid vegetation, only mild valve insufficiency and absence of residual pulmonary infarction.

Infective endocarditis is an uncommon disease. A recent publication has shown that the incidence of IE is about 31 cases per million inhabitants. Right-sided IE represents $10 \%$ of all cases with tricuspid valve involvement in $90 \%$ of cases. Moss and Munt showed the right-sided IE is more frequent in drug-addicts (63\%) [2,3]. We present a case of tricuspid IE complicated by multiple pulmonary septic

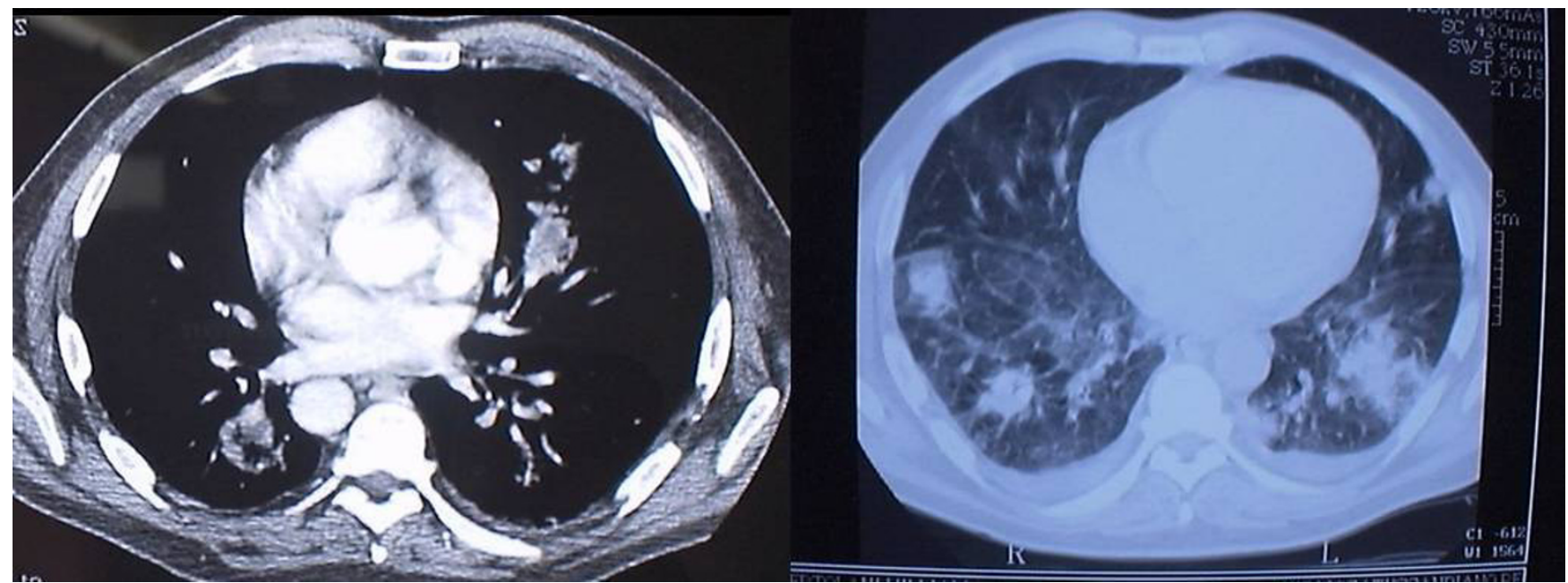

Figure 2

CT scan showing multiple areas of pulmonary infarction. 
infarctions originated probably from a focus of chronic osteomyelitis. The interesting aspect of this case is not only the acute clinic presentation but also the high grade of clinical resistance to the different antibiotic regimens used [4]. The patient did not respond to the use of glycopeptides, teicoplanin and vancomycin always in association with other drugs despite the positive in vitro susceptibility to these antibiotics [5]. The use of linezolid [6], a wide spectrum antibiotic, with a very good reported action on the lungs [7] resulted ineffective with a concomitant dramatic deterioration of the clinical condition of the patient. The use of quinupristin/dalfopristin [8] as salvage therapy resulted in a very quick improvement after three days and resulted in complete cure of tricuspid valve IE and septic embolic lung abscesses. The antibiotic therapy was continued for four weeks as recommended by the American Heart Association guidelines [9] for complicated right-sided endocarditis diminishing the rate of relapses due. The decision to perform a left above-theknee amputation was considered as the only possible guarantee of removal of chronic osteomyelitis focus and was performed with the patient on quinupristin/dalfopristin antibiotic treatment.

\section{Conclusion}

In this paper, we firstly reported a non-operated patient with tricuspid valve endocarditis by MRSA complicated by multiple pulmonary septic infarction cured with quinupristin/dalfopristin. The use of these antibiotic agents opens new perspectives in the management of severely ill patients with invasive valve endocarditis infection.

\section{Abbreviations}

MRSA: Methicillin-resistant S. aureus

IE: infective endocarditis

TTE: Transthoracic echocardiography

TEE: Transesophageal echocardiography

MIC: minimal inhibitory concentration

\section{Competing interests}

The author(s) declare that they have no competing interests.

\section{Authors' contributions}

AC, GC, were involved in conception, design and drafting. CAM and TG made a critical revision of the manuscript. FB, GG participated in the writing of the first draft. All authors improved the manuscript and approved its final version.

\section{References}

I. Hoen B, Alla F, Selton-Suty C, Beguinot I, Bouvet A, Briancon S, Casalta JP, Danchin N, Delahaye F, Etienne J, Le Moing V, Leport C, Mainardi JL, Ruimy R, Vandenesch F: Changing Profile of Infective Endocarditis. Result of a year survey in France. JAMA 2002, 288:75-8I.

2. Moss $R$, Munt $B$ : Injection drug use and right side endocarditis. Heart 2003, 89:577-58I.

3. Abraham J, Mansour C, Veledar E, Khan B, Lerakis S: Staphylococcus Aureus bacteremia and Endocarditis: the Grady Memorial Hospital experience with meticillin-sensitive $S$ aureus and meticillin-resistant $S$ aureus bacteremia. Am Heart J 2004, I 47:536-539.

4. Eliopoulos GM: Current and new antimicrobial agents. Am Heart J 2004, 147:587-592.

5. Woods CW, Cheng AC, Fowler VG Jr, Moorefield M, Frederick J, Sakoulas G, Meka VG, Tenover FC, Zwadyk P, Wilson KH: Endocarditis caused by Staphylococcus Aureus with reduced susceptibility to Vancomycin. Clini Infect Dis 2004, 38: I088-I09I.

6. Ruiz EM, Guerrero IC, Tuazon CU: Endocarditis caused by Methicillin resistant Staphylococcus Aureus : treatment failure with linezolid. Clin Infect Dis 2002, 35: I018-1020.

7. Honeybourne D, Tobin C, Jevons G, Andrews J, Wise R: Intrapulmonary penetration of linezolid. J Antimicrob Chemother 2003, 5 I: 143 |- | 434.

8. Drew RH, Perfect JR, Srinath L, Kurkimilis E, Dowzicky M, Talbot GH: Treatment of methicillin-resistant Staphylococcus aureus infections with quinupristin/dalfopristin in patients intolerant of or failing prior therapy. J Antimicrob Chemother 2000, 16:775-784.

9. Bonow RO, Carabello B, de Leon AC Jr, Edmunds LH Jr, Fedderly BJ, Freed MD, Gaasch WH, McKay CR, Nishimura RA, O'Gara PT, O'Rourke RA, Rahimtoola SH, Ritchie JL, Cheitlin MD, Eagle KA, Gardner TJ, Garson A Jr, Gibbons RJ, Russell RO, Ryan TJ, Smith SC Jr: ACCIAHA Guidelines for the Management of Patients With Valvular Heart Disease. Executive Summary. A report of the American College of Cardiology/American Heart Association Task Force on Practice Guidelines (Committee on Management of Patients With Valvular Heart Disease). J Heart Valve Dis 1998, 7(6):672-707.

\section{Pre-publication history}

The pre-publication history for this paper can be accessed here:

http://www.biomedcentral.com/1471-2334/6/124/pre pub

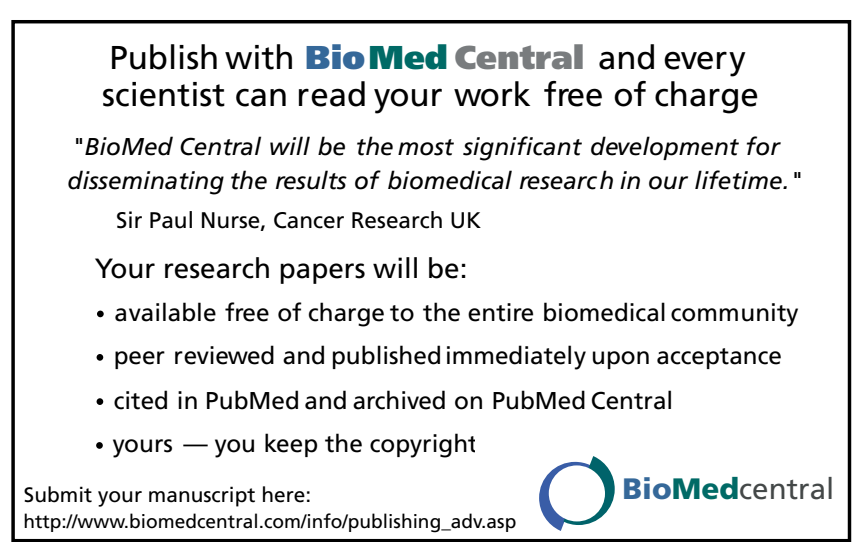

